\title{
ESTUDO DO PROCESSO DE HIDROLISE DE RESÍDUOS LIGNOCELULÓSICOS DO MILHO PARA PRODUÇÃO DE BIOETANOL
}

\author{
R. C.VIEIRA, D. P. C. ANTUNES'1, M. C. S. SILVA¹, R. M. R. G. ALMEIDA ${ }^{1}$ \\ ${ }^{1}$ Universidade Federal de Alagoas, Centro de Tecnologia, Curso de Engenharia Química \\ E-mail: rosana1correia@hotmail.com
}

\begin{abstract}
RESUMO - A grande dependência de fontes de energia não renováveis e poluentes, tem levado a busca de novas rotas para produção de etanol combustível a partir de biomassas residuais de composição lignocelulósica, como por exemplo, palha e sabugo do milho. O objetivo do trabalho foi estudar a influência das condições de hidrólise enzimática na conversão dos açúcares presentes nos resíduos do milho. Inicialmente foi feito o pré-tratamento com $\mathrm{H}_{2} \mathrm{SO}_{4}$, visando à remoção da lignina, hemicelulose e extrativos. Em seguida, foram realizados ensaios de hidrólises enzimáticas, com 16,7 g/L de substrato, utilizando 1,0 e 2,0 mL da enzima comercial celulase de Aspergillus niger, em tampão acetato com $\mathrm{pH} 4,5$. As amostras foram colocadas em mesa incubadora rotativa, tipo Shaker, à $50^{\circ} \mathrm{C}$ durante 48 horas e 72 horas, logo em seguida foi realiza analise dos açúcares redutores (AR) e açúcares redutores totais (ART) para cada ensaio. A melhor condição encontrada para os dois resíduos foi 48 horas de hidrólise e $1,0 \mathrm{~mL}$ da enzima comercial, obtendo-se $0,14 \mathrm{~g}$ de $\mathrm{AR} / \mathrm{g}$ de palha hidrolisada e $0,07 \mathrm{~g}$ de AR por $\mathrm{g}$ de sabugo.
\end{abstract}

\section{INTRODUÇÃO}

O crescimento exacerbado da população e a exploração indiscriminada dos recursos naturais tendem ao seu esgotamento. A busca de novas matrizes energéticas renováveis em substituição aos combustíveis fósseis tem sido importante, visto que, além de serem abundantes, como a celulose, apresentam baixo impacto ambiental. $\mathrm{O}$ desenvolvimento agrícola tem resultado no crescimento da quantidade de resíduos que muitas vezes se acumulam tornando-se problema ambiental. O Brasil, por exemplo, produziu em 2007 aproximadamente 400 milhões de toneladas de subprodutos agroflorestais, incluindo os resíduos gerados na indústria de celulose (NUNES et $a l ., 2001$ ), podendo ser utilizado como matéria-prima na obtenção de energia renovável, como a produção de bioetanol.

O etanol é utilizado como combustível, em grande escala no Brasil, Estados Unidos e em alguns países europeus. Por promover maior calor de vaporização e deter elevada octanagem, pode ser misturado aos derivados do petróleo, como a gasolina ou usado puro em motores específicos, além de ser um excelente combustível para motores híbridos. Quase todo etanol combustível é produzido por fermentação de sacarose no Brasil ou glicose de milho nos Estados 


\section{9 a 22 de outubro de 2014 \\ Florianópolis/SC}

Unidos, porém, estas matérias-primas não são suficientes para satisfazer a demanda internacional (HAHN-HAGERDAL et al., 2006).

Então, a tendência de estudo está voltada para o desenvolvimento de processos biotecnológicos que permitam a utilização de biomassas residuais de composição lignocelulósica para a produção de etanol chamado de segunda geração, como os resíduos do milho, palha e sabugo. As tecnologias para a obtenção de bioetanol de segunda geração, produzido a partir de materiais lignocelulósicos, envolvem a hidrólise dos polissacarídeos da biomassa em açúcares fermentáveis e sua posterior fermentação (SILVA et al., 2010).

A composição e a estrutura da biomassa têm forte influência na natureza e nos rendimentos dos processos de hidrólise e fermentação. Os materiais lignocelulósicos são formados por estruturas duras e fibrosas, compostas majoritariamente pelos polissacarídeos celulose e hemicelulose (cerca de $70 \%$ da massa seca), entremeados por outra macromolécula (DURÁN et al., 1998). A celulose é constituída por polímeros de hexoses (glicose) e a hemicelulose de polímeros de pentoses (xilose, entre outros) o que os torna atrativos para a extração dos monômeros de açúcares (PEREIRA et al., 2008). Os resíduos do milho tem a seguinte composição parcial: a palha possui 37,6\% de celulose, $34,5 \%$ de hemicelulose e $12,6 \%$ de lignina, já o sabugo é composto por $31,7 \%$ de celulose, $34,7 \%$ de hemicelulose e $20,3 \%$ de lignina (SILVA et al., 2010).

A maior dificuldade para o aproveitamento dos resíduos lignocelulósicos está representada pela barreira física formada pela lignina, o que impede o aproveitamento da celulose na forma inativa (DURÁN et al., 1998). Em consequência, a hidrólise enzimática da biomassa normalmente envolve inicialmente o pré-tratamento para romper o selo de lignina e destruir a cristalinidade da celulose (SILVA et al., 2010). Se o pré-tratamento for muito agressivo, os açúcares liberados podem ser degradados em compostos inibidores das enzimas diminuindo o rendimento. Entretanto, se condições muito brandas de pré-tratamento são usadas, isto irá resultar em pequena acessibilidade para a enzima (SENDELIUS et al., 2005).

A degradação da celulose em glicose é realizada por enzimas altamente específicas e catalisadores do processo, as celulases, produzidas por microrganismos diversos. As celulases hidrolisam a celobiose e oligossacarídeos solúveis de baixo grau de polimerização (menor que 7), sendo a glicose o principal destes (SILVA et al., 2010).

A hidrólise de materiais lignocelulósicos pode ser feita por diversos processos, entre os principais estão a rota enzimática, a hidrólise básica e a hidrólise ácida (REYER et al., 1998). Atualmente a hidrólise enzimática tem sido escolhida como a melhor opção para hidrólise de materiais celulósicos, principalmente pelo menor impacto ambiental e consequente redução dos custos de descarte de resíduos (NUNES et al., 2001), além do fato de ser realizada em condição amena de temperatura (CARRASCO, 1998). Alguns fatores afetam a hidrólise enzimática da celulose, como o substrato, a atividade das celulases, as condições de $\mathrm{pH}$ e temperatura das reações (NUNES et al., 2001), que podem ser analisados para otimização da mesma. 
Este trabalho teve como objetivo aperfeiçoar o processo de hidrólise dos resíduos lignocelulósicos do milho, a palha e o sabugo, pela celulase comercial Aspergillus Níger sp com o intuito de se obter etanol de segunda geração $(2 \mathrm{G})$.

\section{MATERIAIS E MÉTODOS}

\subsection{Obtenção da Farinha do Sabugo e Palha do Milho}

O milho utilizado nesta etapa foi selecionado de um único lote provindo da feira livre da cidade de Maceió, sendo considerado o aspecto e aparência. Ele foi descascado manualmente, a palha foi reservada do restante do milho, passando pela higienização, secagem e trituração, obtendo-se a farinha. $\mathrm{O}$ milho teve os grãos retirados e o sabugo foi conservado a temperatura ambiente, ou seja, aproximadamente $30^{\circ} \mathrm{C}$. $\mathrm{O}$ sabugo resultante também passou pelas mesmas etapas da palha para obtenção da farinha. As palhas e os sabugos foram triturados no Laboratório de Sistema de Separação e Otimização de Processos - lassop, no Departamento de Engenharia Química na Universidade Federal de Alagoas (UFAL).

\subsection{Métodos Analíticos Para Caracterização das Farinhas}

Foram feitas as seguintes análises para a caracterização da farinha do sabugo e palha do milho: Umidade, ART E AR.

Determinação de umidade (IAL 012/IV): A técnica gravimétrica com emprego do calor é a mais utilizada e baseia-se na determinação da perda de peso do produto submetido ao aquecimento, até peso constante. O resíduo obtido no aquecimento direto é chamado de resíduo seco e, em geral, o processo mais utilizado é o aquecimento direto da amostra a $105^{\circ} \mathrm{C}$. Procedimento: colocou-se estufa a $105^{\circ} \mathrm{C}$ por no mínimo 1 hora cápsula de porcelana ou de metal previamente identificada. Transferir para o dessecador por no mínimo 15 min e pesar em balança analítica. Pesar 2 a $10 \mathrm{~g}$ de amostra neste recipiente previamente tarado. Levar para a estufa a $105^{\circ} \mathrm{C}$ por 3 horas, esfriar em dessecador por no mínimo 15 min e pesar. Repetir as operações de aquecimento e resfriamento até peso constante da amostra (ou diferença na última casa decimal da balança) e calculado a partir da equação 1:

$$
\text { Umidade }(\%)=100 \mathrm{~N} / \mathrm{P}
$$

$\mathrm{N}=$ perda de peso (massa final menos a tara da cápsula); $\mathrm{P}=$ massa tomada da amostra

Determinação de açúcares redutores totais (A.R.T) (Método do DNS proposto por Miller (1954)):Procedimento: transferiu-se 1,0 a 2,0g de amostra para cada erlenmeyer, misturou-se à amostras $50 \mathrm{ml}$ de água destilada, os levou a mesa incubadora rotativa, tipo Shaker, com $150 \mathrm{rpm}$ por cerca de $30 \mathrm{~min}$. Após este tempo as amostras foram retiradas e filtradas, a porção solida foi armazenada e o licor foi recolhido para a análise dos açucares. Hidrólise: Em tubos de ensaio com tampa adicionou-se $1 \mathrm{ml}$ das amostras (Licor) e $5 \mathrm{~mL}$ de $\overline{\mathrm{H}_{2} \mathrm{SO}_{4}} 1,5 \mathrm{M}$, levou-se ao banho 


\section{9 a 22 de outubro de 2014 \\ Florianópolis/SC}

fervente por $20 \mathrm{~min}$, a $110^{\circ} \mathrm{C}$ e agitou-se ocasionalmente para hidrolisar os polissacarídeos e outros açúcares não-redutores (ao menos a cada $5 \mathrm{~min}$ ). Em seguida os tubos foram mergulhados no banho de gelo para resfriar. Neutralização: Despejou-se o conteúdo dos tubos em beckeres, adicionou 3 gotas de fenolftaleína, fez-se a titulação com hidróxido de sódio $(\mathrm{NaOH})$ a $26 \%$ até a mudança da cor inicial para a cor rósea e posteriormente adicionou-se ácido sulfúrico $\left(\mathrm{H}_{2} \mathrm{SO}_{4}\right)$ $1,5 \mathrm{M}$ até ficar incolor. Diluição: Homogeneizou-se as amostras e transferiu-se para proveta, completando o volume com água destilada até $50 \mathrm{~mL}$. O tubo e o becker foram risados com água destilada antes de completar o volume. Reação de DNS: a determinação foi feita de forma semelhante à reação para determinação de açúcares redutores.

Determinação de açúcares redutores (A.R) (Método do DNS proposto por Miller (1954)): Procedimento: Reação de DNS: transferiu-se $0,25 \mathrm{~mL}$ da amostra para um tubo de ensaio com tampa e adicionou-se $0,5 \mathrm{~mL}$ de água destilada. Verificou-se se o banho de água estava fervendo. Adicionou-se, então, 0,25 mL do reagente de DNS e a amostra foi levada para banho fervente por 5min, permitindo assim a reação entre a glicose e o DNS. Resfriou-se o tubo em banho de gelo, ajustou-se o volume com água destilada para $5 \mathrm{~mL}$ (ou seja, adicionou-se $4 \mathrm{~mL}$ de água) e então foi feita a leitura da absorbância em espectofotometro à $540 \mathrm{~nm}$, tendo como padrão concentrações conhecidas de glicose. A partir desses dados obteve-se a curva padrão por regressão linear e, a seguir, a equação da reta que permitiu calcular a concentração de glicose em cada amostra (Equação 2) (g de glicose/g de amostra). Obs: para "zerar" o espectrofotômetro e ler as absorbâncias foi necessário se fazer um branco, substituindo-se na reação de DNS a amostra por água destilada.

Sendo as concentrações de A.R. e A.R.T. obtidos a partir dos fatores das Equações 2 e 3, respectivamente:

$$
\begin{aligned}
& Y=6,787 \times X \\
& Y=8,213 \times X
\end{aligned}
$$

Onde: Y é a concentração de glicose; X é a leitura de absorbância;

\subsection{Pré-tratamento da Matéria-Prima}

Antes da hidrólise enzimática foi realizada a deslignificação do sabugo e palha do milho, em pré-tratamento por explosão a vapor, por meio de um reator do tipo autoclave. Foram utilizadas cerca de $200 \mathrm{~g}$ da matéria-prima, da palha e do sabugo, 2 litros de solução ácida, de ácido sulfúrico $\left(\mathrm{H}_{2} \mathrm{SO}_{4}\right)$ a $0,5 \%$, misturando-se os mesmos em erlenmeyers e ,em seguida, fechando-os com papel alumínio. Os erlemneyers foram levados os autoclave por 15 min a 1 atm, após este tempo os mesmos foram retirados e resfriados. Após a deslignificação, a polpa foi separada do licor por filtração, e efetuada várias lavagens com água quente a $70{ }^{\circ} \mathrm{C}$, para que fosse retirada a lignina que ainda encontrava-se impregnada no material. Posteriormente, foi feita a analise de umidade (IAL 012/IV), AR e ART (Miller (1954)). 


\subsection{Hidrólise Enzimática no Material}

Na hidrólise enzimática o peso do pré-tratado, de sabugo e palha utilizados, foram fixos, $1 \mathrm{~g}$ de cada, variando apenas o tempo de hidrolise, $48 \mathrm{~h}$ e $72 \mathrm{~h}$ e a quantidade da enzima comercial Cellulase Aspergillus Niger sp (E.C.3.2.1.4), 1,0 e 2,0 mL. Os ensaios de hidrolise foram realizados em frascos de erlenmeyer contendo cerca de $1 \mathrm{~g}$ de cada pré-tratado (em duplicata), 60 mL do liquido de mistura (formado por solução de tampão acetato, à $0,1 \mathrm{M} \mathrm{e} \mathrm{pH} \mathrm{em} \mathrm{torno} \mathrm{de} \mathrm{4,5)}$ e a enzima comercial. Misturou-se no frasco inicialmente, a solução tampão à massa do prétratado ajustando-se o $\mathrm{pH}$, com auxílio do pHmetro, em torno de $\mathrm{pH} 4,5$, em seguida adicionouse a quantidade da enzima comercial pré-determinada. Os frascos foram mantidos em mesa incubadora rotativa, tipo Shaker, com $150 \mathrm{rpm}$, por tempos pré-determinados, os ensaios foram dispostos na Tabela 1:

Ao final de cada ensaio de hidrólise, foram realizadas as análises de açúcares redutores (AR) e açúcares redutores totais (ART) pelo método do DNS proposto por Miller (1954), visando selecionar as condições experimentais nas quais se obtém a maior quantidade de açúcares fermentáveis.

Tabela 1 - Condições de hidrólise.

\begin{tabular}{|c|c|c|}
\hline & Tempo de Hidrolise $(\mathrm{h})$ & Quantidade de Enzima commercial (ml) \\
\hline $1^{\circ}$ Ensaio & 48 & 1,0 \\
\hline $2^{\circ}$ Ensaio & 48 & 2,0 \\
\hline $3^{\circ}$ Ensaio & 72 & 1,0 \\
\hline $4^{\circ}$ Ensaio & 72 & 2,0 \\
\hline
\end{tabular}

\section{RESULTADOS E DISCUSSÕES}

Após a realização dos métodos analíticos para a caracterização das amostras obteve-se os dados encontrados da Figura 1, onde a concentração da farinha de cada matéria-prima para a realização das analises de AR e ART foi de $40 \mathrm{~g} / \mathrm{L}$ : 


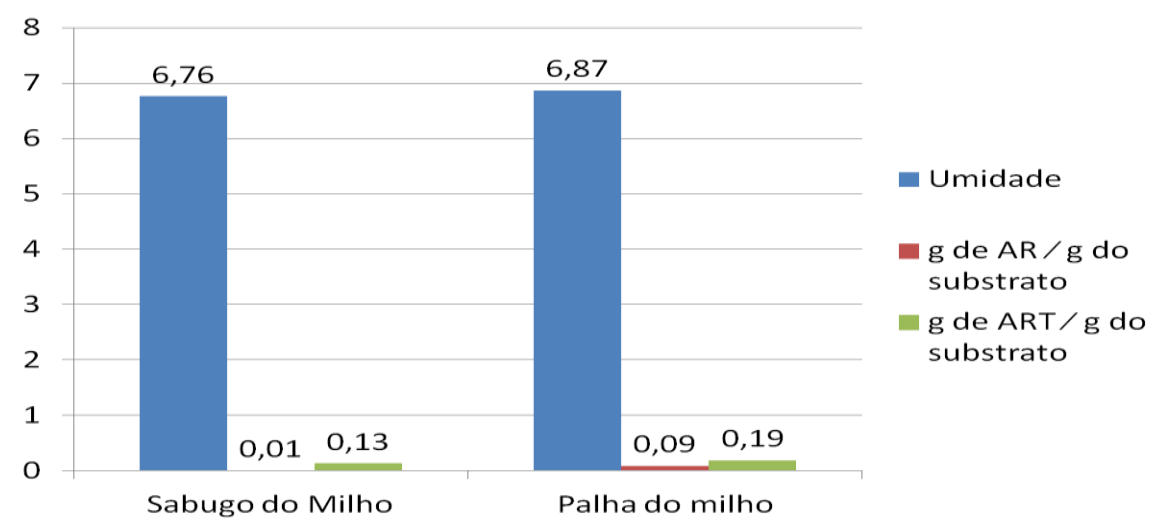

Figura 1 - Características físico-químicas do sabugo e palha do milho in natura.

O valor do teor de umidade esta relacionado ao fato das amostras encontrar-se in natura, assim como o teor de AR e ART. Após a realização do pré-tratamento ácido das farinhas, foram obtidos os devidos teores de umidade, AR e ART, que se encontram no Figura 2, onde a concentração inicial do pré-tratamento foi de $100 \mathrm{~g} / \mathrm{L}$ para palha e sabugo do milho.

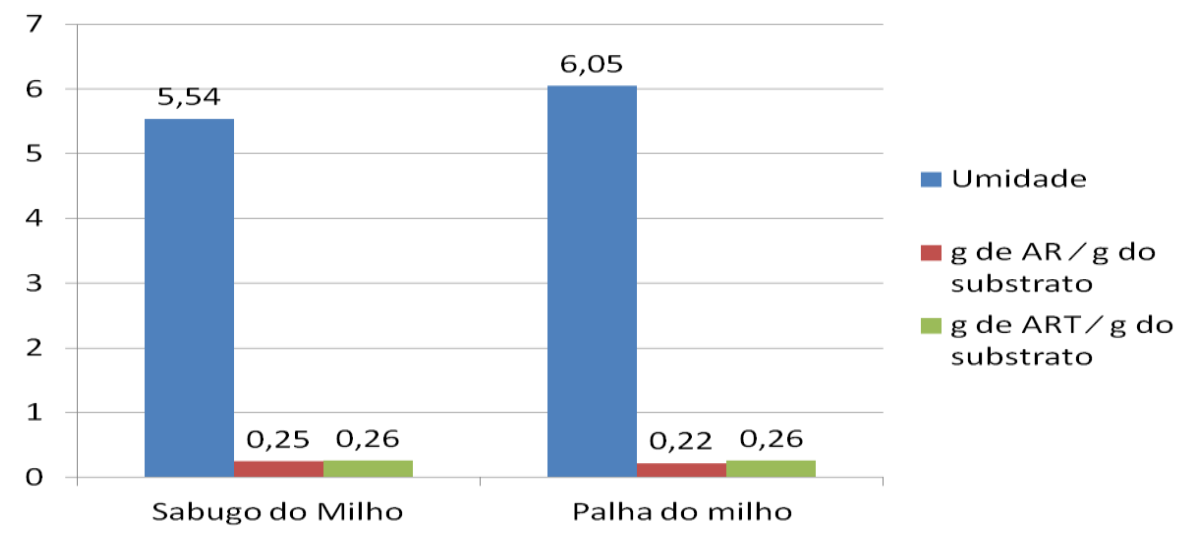

Figura 2 - Teores de umidade, AR e ART após o pré-tratamento do bagaço e palha do milho.

$\mathrm{Na}$ terceira etapa foram realizados inúmeros ensaios de hidrólise, ocorrendo ajustes ao longo dos mesmos, a fim de se obter as melhores condições de hidrólise. Assim, os quatro principais ensaios e seus respectivos valores de AR e ART, variando-se a quantidade da enzima comercial e o tempo de hidrólise, estão representados na Figura 3: 


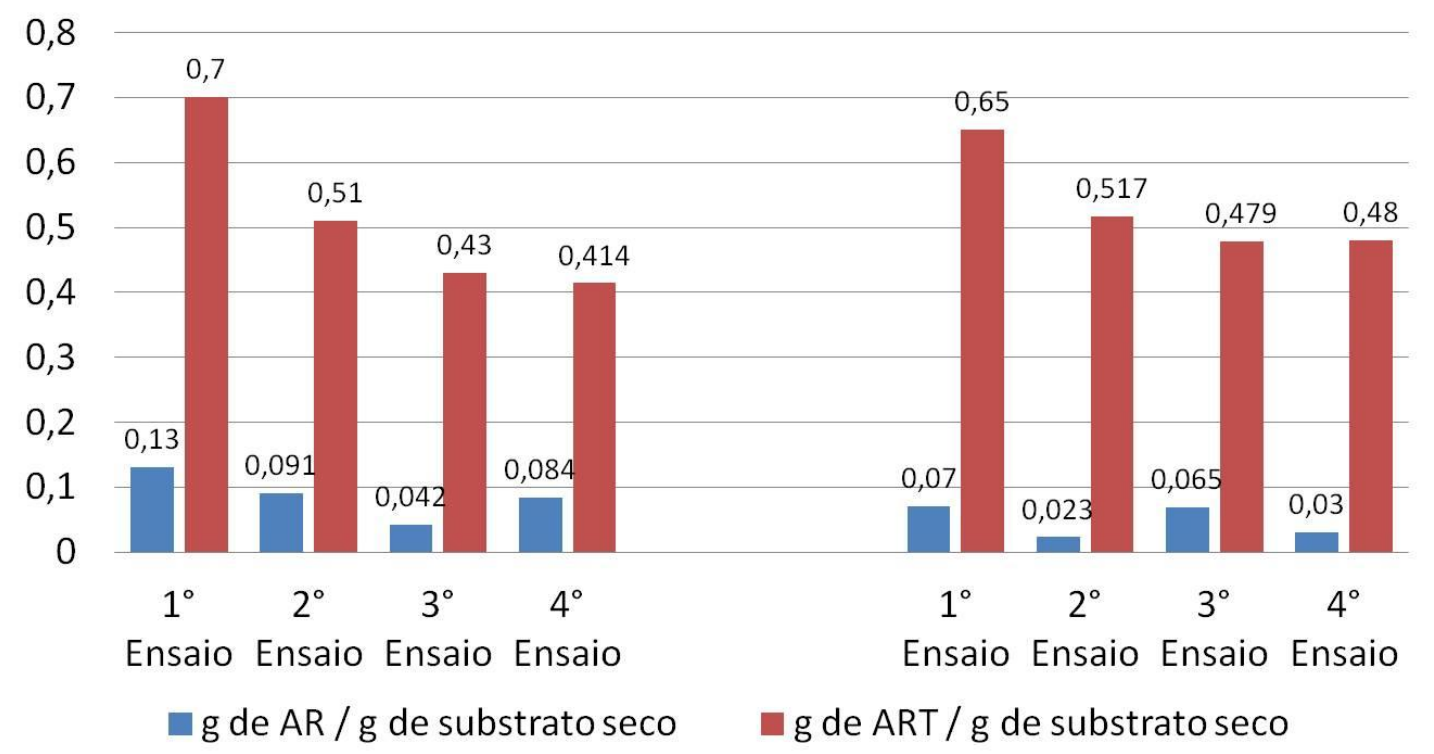

Figura 3 - Valores de AR e ART da palha e sabugo do milho, respectivamente, obtidos nos ensaios.

Dentre os quatro ensaios realizados, o primeiro ensaio foi que apresentou melhor resultado de A.R. e A.R.T., tanto para a palha quanto para o sabugo do milho, entendendo assim que usando o tempo de hidrólise de $48 \mathrm{~h}$ e uma quantidade da enzima comercial de 1,0 mL, obtém-se uma melhor quantidade de açúcares fermentáveis. Sabendo-se que na produção do álcool industrial, parte-se de uma concentração baixa de açucares (12 a 14\%) para se obter desdobramento total em 24 a 48 horas, sem que a levedura seja inibida pelo teor alcoólico final, já que o aumento do teor alcoólico do mosto em fermentação inibe o desenvolvimento da própria levedura, no geral este cessa em concentrações de $1 \%$ à $12 \%$ do álcool.

Dentre os fatores que podem ter promovido uma concentração mais baixa de glicose no tempo de $72 \mathrm{~h}$, tem-se o fato de que pode ter ocorrido uma variação de $\mathrm{pH}$ fora da faixa ideal de trabalho da enzima. Também pode ter acontecido uma inibição da mesma por contaminantes gerados no pré-tratamento presentes ainda na matéria pré-tratada, a lignina, que não foi suficientemente quebrada para deixar a celulose bem exposta, entre outros. Possíveis erros experimentais podem ter ocorrido nos ensaios de $48 \mathrm{~h}$ visto que os teores de açúcares obtidos foram de encontro ao esperado, pois após o pré-tratamento com posterior hidrólise espera-se que maiores teores de açúcares sejam obtidos conforme se utilize maiores volumes de enzima.

\section{CONCLUSÕES}

Observando os valores de ART e AR em cada ensaio foi constatado que todos tiveram uma quantidade considerável de açúcares, ou seja, as concentrações de glicose em cada amostra foram 
muito boas, em comparação com a quantidade de glicose necessária para uma boa fermentação, tendo o melhor resultado de ART e AR na condição de hidrolise 48horas e 1,0 mL de enzima comercial.

\section{REFERÊNCIAS}

AQUARONE, E.; BORZANI, W.; LIMA, U. A.; SCHMIDELL, W.. Biotecnologia industrial: processos fermentativos e enzimáticos. 1.ed. São Paulo: Editora Edgard Blücher LTDA. 593p. 4v. v.3, p.1-39, 2001;

CARRASCO, F. ThermomechanochemicalPretreatment of Wood in A Process-Development Unit. Wood Science andTechnology, v. 26 (6): 413-28, 1998;

DURÁN, N.;ZAMORA, P.P.;REYES, J.; Hidrólise enzimática de casca de arroz utilizando-se celulases. Efeito de tratamentos químicos e fotoquímicos. Química nova, v.21, n.2 ,p.140-143, 1998;

HAHN-HAGERDAL, B.; GALBE, M.; GORWA-GRAUSLUND, M. F.; LIDÉN G. e ZACCHI G. Bio-ethanol - the fuel of tomorrow from the residues of today. TRENDS in Biotechnology, v.24, n.12, p.549-556, 2006;

NUNES, J. M. N.; CARVALHO, P. I. N.; PINHEIRO, I. R. Estudo da hidrólise de bagaço de cana-de-açúcar pré-tratado com peróxido de hidrogênio. XVIII Simpósio Nacional de Bioprocessos, Caixias do Sul/RS, 2001;

PEREIRA Jr., N.; COUTO, M.A.P.G.; SANTA ANNA, L.M.M.. Biomass of lignocellulosic composition for fuel ethanol production and the context of biorefinery. In Series on Biotechnology, Ed. Amiga Digital UFRJ, Rio de Janeiro, v.2, 45 p, 2008;

REYER, J.; ZAMOURA, P. P.; DURÁN, N. Hidrólise enzimática da casca de arroz utilizando-se celulases. Efeito de tratamentos químicos e fotoquímicos. Química Nova, v. 21, n. 2, p. 140-143, 1998;

SENDELIUS J.. Steam pretreatment optimization for sugarcane bagasse in bioethanol. Master of Science Thesis. Department of Chemical Engineering, Lund University, Sweden, 2005;

SILVA, N. L. C. Produção de bioetanol de segunda geração a apartir de biomassa residual da industria de celulose. Dissertação de mestrado do programa de Pós-graduação em tecnologia de Processos Químicos e Bioquímicos. Escola de Química, Universidade Federal do Rio de Janeiro, UFRJ, 2010. 